\title{
Does noise affect learning? A short review on noise effects on cognitive performance in children
}

\author{
Maria Klatte *, Kirstin Bergström and Thomas Lachmann \\ Center for Cognitive Science, Cognitive and Developmental Psychology Laboratory, University of Kaiserslautern, Kaiserslautern, Germany
}

\section{Edited by:}

Nicole Wetzel, University of Leipzig,

Germany

Reviewed by:

Patrik Sörqvist, University of Gävle, Sweden

Emily M. Elliott, Louisiana State

University, USA

*Correspondence:

Maria Klatte, Department of

Psychology, Cognitive and

Developmental Psychology

Laboratory, University of

Kaiserslautern,

Erwin-Schroedinger-Strasse 57,

67663 Kaiserslautern, Germany

e-mail:klatte@rhrk.uni-kl.de
The present paper provides an overview of research concerning both acute and chronic effects of exposure to noise on children's cognitive performance. Experimental studies addressing the impact of acute exposure showed negative effects on speech perception and listening comprehension. These effects are more pronounced in children as compared to adults. Children with language or attention disorders and second-language learners are still more impaired than age-matched controls. Noise-induced disruption was also found for non-auditory tasks, i.e., serial recall of visually presented lists and reading. The impact of chronic exposure to noise was examined in quasi-experimental studies. Indoor noise and reverberation in classroom settings were found to be associated with poorer performance of the children in verbal tasks. Regarding chronic exposure to aircraft noise, studies consistently found that high exposure is associated with lower reading performance. Even though the reported effects are usually small in magnitude, and confounding variables were not always sufficiently controlled, policy makers responsible for noise abatement should be aware of the potential impact of environmental noise on children's development.

Keywords: noise, cognitive performance, cognitive development, children, speech perception, listening comprehension, irrelevant sound effect, classroom acoustics
In everyday life, cognitive tasks are often performed in the presence of task-irrelevant environmental noise. Accordingly, numerous studies on noise effects on performance have been conducted since the middle of the 20th century (for reviews see Hellbrück and Liebl, 2007; Szalma and Hancock, 2011), showing thatdepending on characteristics of sounds and tasks - noise of low to moderate intensity may in fact evoke substantial impairments in performance.

Most of these studies were conducted with adults. The present review, however, will focus on studies including children. Children are especially vulnerable to harmful effects of environmental noise, as cognitive functions are less automatized and thus more prone to disruption. We will report findings concerning effects of acute noise on performance in concurrent auditory and non-auditory tasks, as well as effects of chronic noise on children's cognitive development.

\section{EFFECTS OF ACUTE NOISE ON CHILDREN'S PERFORMANCE IN AUDITORY TASKS}

Psychoacoustic studies have consistently shown that children's speech perception is more impaired than adults' by unfavorable listening conditions. The ability to recognize speech under conditions of noise or noise combined with reverberation improves until the teenage years (Johnson, 2000; Wightman and Kistler, 2005; Talarico et al., 2007; Neuman et al., 2010). With stationary noise makers, signal-to-noise ratios (SNRs) have to be 5-7 dB higher for young children when compared to adults in order to achieve comparable levels of identification of speech or nonspeech signals, with adult-like performance reached at about 6 years of age (Schneider et al., 1989; Fallon et al., 2000;
Werner, 2007). However, with maskers that vary over time, i.e., with trial-by-trial variation of the maskers' spectral composition (Oh et al., 2001; Hall et al., 2005; Leibold and Neff, 2007) or with fluctuating maskers such as single-talker speech (Wightman and Kistler, 2005), adult-like performance is usually not reached before the age of 10 years. Furthermore, children are less able than adults to make use of spectro-temporal and spatial cues for separation of signal and noise (Wightman et al., 2003; Hall et al., 2005). These findings demonstrate that children are especially prone to informational masking, i.e., masking that goes beyond energetic masking predicted by filter models of the auditory periphery.

Studies identified a range of linguistic and cognitive factors to be responsible for children's difficulties with speech perception in noise: concerning the former, children are less able than adults to use stored phonological knowledge to reconstruct degraded speech input. This holds for the level of individual phonemes, as children's phoneme categories are less well specified than adults' (Hazan and Barrett, 2000), but also for the lexical level since children's phonological word representations are more holistic and less segmented into phoneme units. Therefore the probability of successfully matching incomplete speech input with stored long-term representations is reduced (Nittrouer, 1996; Metsala, 1997; Mayo et al., 2003). In addition, young children are less able than older children and adults to make use of contextual cues to reconstruct noise-masked words presented in sentential context (Elliott, 1979). Concerning attention, children's immature auditory selective attention skills contribute to their difficulties with speech-in-noise perception. Children's susceptibility to informational masking has been attributed to 
deficits in focusing attention on auditory channels centered on signal frequencies, while ignoring nonsignal channels (Wightman and Kistler, 2005). Behavioral and ERP measures from dichotic listening paradigms provide evidence that auditory selective attention improves throughout entire childhood (Doyle, 1973; Pearson and Lane, 1991; Coch et al., 2005; Wightman et al., 2010; Gomes et al., 2012).

Owing to the mediating role of linguistic competence and selective attention, children with language or attention disorders are still more impaired than normally developing children by noise in speech perception tasks (Geffner et al., 1996; Ziegler et al., 2005, 2009). A stronger noise effect is also evident for children tested in their second language when compared to native children (Crandell and Smaldino, 1996). Studies with adults revealed that even skilled non-native listeners, whose performance in quiet is comparable to that of native listeners, are outperformed by native listeners under conditions of noise or noise combined with reverberation (Rogers et al., 2006; for review see Lecumberri et al., 2010).

Studies reviewed so far focused on simple tasks requiring identification of isolated speech targets in noise. However, listening in everyday situations, e.g., in classrooms, goes far beyond identification of single words or syllables. Effective listening in these situations requires semantic and syntactic processing of complex oral information while developing a coherent mental model of the story meaning (Kintsch, 1988). Thus, the question arises how noise affects performance in complex listening tasks. Studies addressing this topic revealed noise-induced decrements in adults' memory for paired associates, sequences of unrelated words, sentences, or discourse, even with SNRs allowing perfect or near-perfect identification of the speech targets (Rabbitt, 1968; Pichora-Fuller et al., 1995; Murphy et al., 2000; Ljung et al., 2009). Only a few studies in this field included children. Klatte et al. (2010a) used a listening task requiring execution of complex oral instructions and found substantial decrements due to single-talker speech and classroom noise in elementary school children. Adults were less affected. Valente et al. (2012) reported significant impairments in discourse comprehension in 8 - to 12-year-olds due to broadband noise combined with reverberation. The noise effects found in these studies could not be attributed to impaired identification. A possible explanation is that identification of degraded speech requires extra resources which are then unavailable for encoding, storage, and processing of the information (McCoy et al., 2005). In addition, age-related improvements in attentional control (e.g., Davidson et al., 2006) may contribute to children's difficulties when performing listening tasks in the presence of noise. Children are less able than adults to ignore irrelevant sounds, and thus are more susceptible to sound-induced disruption in both auditory and non-auditory tasks. We will return to this point in the following section.

To summarize, the reviewed studies document that children need more favorable listening conditions than adults for decoding and processing of oral information [but see Söderlund et al. (2007, 2010) for contrasting findings in inattentive children]. This has practical implications for the acoustical design of classrooms, since effective listening is a linchpin of school learning.
The issue of classroom acoustics has thus gained much interest during the past decades. Studies simulating classroom-like conditions of noise and reverberation reported severe impairments in children's listening performance (Yacullo and Hawkins, 1987; Jamieson et al., 2004; Bradley and Sato, 2008; Klatte et al., 2010a; Neuman et al., 2010; Valente et al., 2012). But even though international and national standards concerning ambient noise levels and reverberation in classrooms were developed in the past decades, many classrooms still do not fit the needs of young listeners (Bradley and Sato, 2008; Klatte et al., 2010b).

\section{EFFECTS OF ACUTE NOISE ON CHILDREN'S PERFORMANCE IN NONAUDITORY TASKS}

Concerning tasks that do not involve auditory targets, studies with adults have consistently shown that especially short-term memory is sensitive to negative effects of noise. Immediate serial recall of visually presented verbal items is reliably impaired by task-irrelevant sounds (for reviews see Hughes and Jones, 2001; Beaman, 2005; Schlittmeier et al., 2012). Impairments occur with single talker speech and non-speech sounds such as tones or instrumental music, but not with continuous broadband noise or babble noise. This so-called irrelevant sound effect (ISE) occurs reliably even with low-intensity sounds, with meaningless speech (e.g., speech in a language unknown to participants), and when sound presentation is confined to a rehearsal phase after encoding of the list items. However, the ISE magnitude is determined by inherent properties of the irrelevant sound. Recall performance is specifically impaired by sounds with a changing-state characteristic, i.e., by auditory streams which consist of distinct auditory-perceptive objects that vary consecutively. For example, irrelevant sounds consisting of different syllables or tones evoke an ISE, whereas steady state sounds, e.g., continuous broadband noise or repetitions of single syllables or tones, have a minor or no effect.

Different theories have been proposed concerning the underlying mechanisms of ISE evocation. Some of these assume that irrelevant sounds have automatic access to working memory, causing specific interference with the retention of cues to serial order (Jones et al., 1995) or-in case of speech-with the retention of phonological codes (Salamé and Baddeley, 1982; Neath, 2000). Other accounts attribute the ISE to the attentional burden caused by the necessity to ignore the sounds (Elliott, 2002).

Several studies found the ISE in elementary school children (Elliott, 2002; Elliott and Cowan, 2005; Klatte et al., 2007, 2010b; Elliott and Briganti, 2012), three of which including different age groups in order to learn about the role of attention in ISE evocation by analyzing developmental change. Elliott (2002) reported a dramatic increase in the magnitude of the ISE on serial recall of visually presented digits with decreasing age. Performance drop relative to quiet was $39 \%$ in the second-graders, as opposed to $11 \%$ in the adults. The age effect was interpreted as evidence for a dominant role of attentional control in ISE evocation. In a recent study of this group (Elliott and Briganti, 2012), the age effect was replicated-albeit smaller in magnitude-but other experiments in the series yielded convincing evidence against the attentional account of the ISE. Klatte et al. (2010b) used serial recall of common nouns presented pictorially and found detrimental effects 
due to background speech which did not differ in magnitude between first-grade children and adults. These and other findings (Hughes et al., 2007, 2012; Röer et al., 2011) suggest that two separate mechanisms contribute to noise-induced impairments in serial recall. On the one hand, irrelevant sounds with a changing state characteristic automatically interfere with maintenance of item or order information in short-term memory. This mechanism is the dominant source of disruption in the standard ISE paradigm, and seems to be adult-like in first-graders. On the other hand, irrelevant sounds may capture attention. The impact of attention capture depends on characteristics of the sound, and on the attentional abilities of the participants. Auditory events that are salient (e.g., of personal significance, such as one's own name), unexpected (e.g., slamming of a door), or deviant from the recent auditory context (e.g., change in voice in a speech stream) have a strong potential to capture attention. Children are more susceptible to sound-induced distraction due to limited attentional control. Accordingly, in Klatte et al. (2010b), firstgraders were also impaired by a mixture of nonverbal classroom sounds, whereas older children and adults were unaffected.

Outside the realm of research on ISE, studies addressed effects of moderate-intensity environmental noise on children's performance in academic tasks. Early studies in this field provided little support for noise-induced impairments (Kassinove, 1972; Johansson, 1983). More recent results are inconsistent. Dockrell and Shield (2006) analyzed effects of babble and babble mixed with traffic sounds on third-graders performance in tests assessing reading, spelling, arithmetic, and attention. For all tests, overall scores were lower with babble noise when compared to quiet. Contrary to prediction, however, reading and spelling was even better in the babble plus traffic noise condition when compared to quiet and babble, and error rates in the attention test were higher in quiet when compared to both noise conditions. These results are difficult to interpret as children were not randomly assigned to noise conditions and instead were tested in their original class settings. As only two classes were assigned to each noise condition and class membership is known to affect academic performance (e.g., Kyriakides et al., 2009), a-priori group differences in the dependent variables cannot be ruled out.

A number of studies investigated the effects of background speech and transportation noise on delayed memory for texts in teenagers. Participants read prose paragraphs under different noise conditions and were later tested for prose memory in silence. Recall performance was impaired by meaningful speech (Hygge et al., 2003; Boman, 2004; Sörqvist, 2010), but not by meaningless speech (Hygge, 2003). Concerning transportation noise, results are inconsistent. Hygge (2003) found impairments due to aircraft noise during encoding. Sörqvist (2010) used a within-subjects design and found no effect of aircraft noise, but severe impairments due to meaningful speech. Hygge et al. (2003) and Hygge (2003) found impairments due to road traffic noise while Boman (2004) did not. Ljung et al. (2009) used a direct measure of online reading comprehension and found no effect of road traffic noise and meaningful speech on 12- to 13-year olds' comprehension scores.

Thus, all except one of the studies found impairments due to meaningful speech. This is in line with studies with adults, showing that meaningful speech evokes stronger impairments than meaningless speech in school-related verbal tasks involving reading (Jones et al., 1990; Oswald et al., 2000; Bell et al., 2008) or story writing (Sörqvist et al., 2012). According to the interference-by-process-account (Marsh et al., 2009), meaningful speech automatically evokes semantic processes which compete with the semantic processes involved in the task. As transportation noise does not evoke such processes, its effect on reading found in some, but not all studies, is presumably due to a more general attention-capture process. In line with this argument, Sörqvist (2010) provided evidence that the participants' attentional abilities have a stronger impact on disruption evoked by transportation noise when compared to meaningful speech. Note, however, that category membership (e.g., transportation noise vs. speech) is not sufficient to predict whether or not a sound will evoke distraction. As outlined earlier, the potential of a sound to capture attention depends on characteristics such as salience, predictability, and deviance from the recent auditory context. Thus, in addition to its specific effects on semantic processing and serial recall, speech noise containing such features is able to act as distractor (Hughes et al., 2012). On the other hand, transportation noise lacking such features has no effect on performance (Klatte et al., 2007).

\section{CHRONIC EFFECTS OF NOISE ON CHILDREN'S COGNITIVE DEVELOPMENT}

In view of the harmful effects of acute noise, the question arises whether enduring exposure to environmental noise may cause persisting deficits in children's cognitive development. Research in this field focused on indoor noise at school and aircraft noise. Concerning the former, studies yielded evidence for chronic effects on children's reading and prereading skills (Maxwell and Evans, 2000; Shield and Dockrell, 2008; Klatte et al., 2010c). Concerning aircraft noise, mixed results were reported with respect to chronic effects on children's attention (Stansfeld et al., 2005; van Kempen et al., 2010; Belojevic et al., 2012) and memory (Haines et al., 2001; Matheson et al., 2010), but exposure to aircraft noise was consistently associated with lower reading performance (see for review, Clark and Sörqvist, 2012). However, some of these studies are difficult to interpret due to methodological limitations. For example, cognitive abilities were usually measured in the children's regular classrooms, but acute noise levels were not always controlled. Thus, testing was done in noisy conditions for the exposed and in quiet conditions for the nonexposed children, resulting in confound of acute and chronic exposure (e.g., Seabi et al., 2012). In addition, aircraft noise has been found to be associated with socioeconomic status (SES) which in turn is strongly related to children's reading abilities. Thus, insufficient control of SES variables in early studies may have lead to an overestimation of the noise effect (Haines et al., 2002).

The hitherto most comprehensive study in this field, the crosssectional RANCH (road-traffic and aircraft noise exposure and children's cognition and health) study (Stansfeld et al., 2005) included children $(N=2844)$ living in the vicinity of huge international airports in the UK, the Netherlands, and Spain. Whereas prior studies confined to comparisons of highly exposed and 
non- exposed children, noise exposure in the RANCH study was included as continuous variable, aiming to reveal the noise levels at which the harmful effects on children's cognition begin. With SES being controlled, the authors found no effect of aircraft noise exposure on sustained attention, working memory, and delayed recall of orally presented stories, but a linear exposure-effect relationship between aircraft noise and decreasing reading comprehension. This effect is often cited as evidence for a causal role of aircraft noise in reading impairment. What is often unreported in the secondary literature is, however, that there was another exposure-effect relationship, revealing enhanced performance in episodic memory with increasing exposure to road traffic noise. This counter-intuitive finding remains unexplained.

Concerning the underlying mechanisms of chronic noise effects, some authors proposed that enduring exposure to noise in early childhood affects the development of basic language functions which are of special importance in reading acquisition (Evans and Maxwell, 1997; Maxwell and Evans, 2000; Klatte et al., 2010c). This is a reasonable argument in view of, on the one hand, the vulnerability of children's speech perception and shortterm memory for disruption due to acute noise, and on the other hand, the important role of these functions in reading acquisition (Baddeley et al., 1998; Steinbrink and Klatte, 2008; Ziegler et al., 2009). In line with this argument, electrophysiological studies

\section{REFERENCES}

Baddeley, A., Gathercole, S., and Papagno, C. (1998). The phonological loop as a language learning device. Psychol. Rev. 105, 158-173. doi: 10.1037/0033-295X.105.1.158

Beaman, C. P. (2005). Auditory distraction from low-intensity noise: a review of the consequences for learning and workplace environments. Appl. Cogn. Psychol. 19, 1041-1064. doi: 10.1002/acp.1134

Bell, R., Buchner, A., and Mund, I. (2008). Age-related differences in irrelevant-speech effects. Psychol. Aging 23, 377-391. doi: 10.1037/0882-7974.23.2.377

Belojevic, G., Evans, G. W., Paunovic, K., and Jakovljevic, B. (2012). Traffic noise and executive functioning in urban primary school children: the moderating role of gender. J. Environ. Psychol. 32, 337-341. doi: 10.1016/j.jenvp.2012.05.005

Boman, E. (2004). The effects of noise and gender on children's episodic and semantic memory. Scand. J. Psychol. 45, 407-416. doi: $\quad 10.1111 / j .1467-9450.2004$. 00422.x

Bradley, J. S., and Sato, H. (2008). The intelligibility of speech in elementary school classrooms. J. Acoust. Soc. Am. 123, 2078-2086. doi: 10.1121/1.2839285

Brattico, E., Kujala, T., Tervaniemi, M., Alku, P., Ambrosi, L. and Monitillo V. (2005). Long-term exposure to occupational noise alters the cortical organization of sound processing. Clin. Neurophysiol. 116, 190-203. doi: 10.1016/j.clinph.2004.07.030

Clark, C., and Sörqvist, P. (2012). A 3 year update on the influence of noise on performance and behavior. Noise Health 14, 292-296. doi: 10.4103/1463-1741.104896

Coch, D., Sanders, L. D., and Neville, H. J. (2005). An event-related potential study of selective auditory attention in children and adults. J. Cogn. Neurosci. 17, 605-622. doi: $10.1162 / 0898929053467631$

Crandell, C. C., and Smaldino, J. J. (1996). Speech perception in noise by children for whom english is a second language. Am. J. Audiol. 5, 47-51.

Davidson, M., Amso, D., Anderson, L., and Diamond, A. (2006). Development of cognitive control and executive functions from 4 to 13 years: evidence from manipulations of memory, inhibition, and task switching. Neuropsychologia 44, 2037-2078. doi: 10.1016/j. neuropsychologia.2006.02.006

Dockrell, J. E., and Shield, B. M. (2006). Acoustical barriers in classrooms: the impact of noise on performance in the classroom. $B r$. Educ. Res. J. 32, 509-525. doi: 10.1080/01411920600635494

Doyle, A.-B. (1973). Listening to distraction: a developmental study of selective attention. J. Exp.

revealed alterations in the cortical responses to speech sounds in individuals with a long-term exposure to occupational noise (Brattico et al., 2005).

\section{CONCLUSIONS}

The reviewed studies document harmful effects of noise on children's learning. Children are much more impaired than adults by noise in tasks involving speech perception and listening comprehension. Non-auditory tasks such as short-term memory, reading and writing are also impaired by noise. Depending on the nature of the tasks and sounds, these impairments may result from specific interference with perceptual and cognitive processes involved in the focal task, and/or from a more general attention capture process.

Concerning chronic effects, despite inconsistencies within and across studies, the available evidence indicates that enduring exposure to environmental noise may affect children's cognitive development. Even though the reported effects are usually small in magnitude, they have to be taken seriously in view of possible long-term effects and the accumulation of risk factors in noiseexposed children (Evans, 2004). Obviously, the findings reported in this review have practical implications for the acoustical design of schools, for the placement of schools in the vicinity of airports, and for the policy of noise abatement.

Child Psychol. 15, 100-115. doi: 10.1016/0022-0965(73)90134-3

Elliott, E. M. (2002). The irrelevantspeech effect and children: theoretical implications of developmental change. Mem. Cognit. 30, 478-487. doi: 10.3758/BF0319 4948

Elliott, E. M., and Briganti, A. M. (2012). Investigating the role of attentional resources in the irrelevant speech effect. Acta Psychol. 140, 64-74. doi: 10.1016/j.actpsy.2012.02.009

Elliott, E. M., and Cowan, N. (2005). Coherence of the irrelevantsound effect: individual profiles of short-term memory and susceptibility to task-irrelevant materials. Mem. Cognit. 33, 664-675. doi: 10.3758/BF03195333

Elliott, L. L. (1979). Performance of children aged 9 to 17 years on a test of speech intelligibility in noise using sentence material with controlled word predictability. J. Acoust. Soc. Am. 66, 651. doi: 10.1121/1.383691

Evans, G. W. (2004). The environment of childhood poverty. Am. Psychol. 59, 77-92. doi: 10.1037/0003-066X.59.2.77

Evans, G., and Maxwell, L. (1997). Chronic noise exposure and reading deficits: the mediating effects of language acquisition. Environ. Behav. 29, 638-656. doi: 10.1177/001391 6597295003
Fallon, M., Trehub, S. E., and Schneider, B. A. (2000). Children's perception of speech in multitalker babble. J. Acoust. Soc. Am. 108, 3023-3029. doi: 10.1121/1.1323233

Geffner, D., Lucker, J. R., and Koch, W. (1996). Evaluation of auditory discrimination in children with ADD and without ADD. Child Psychiatry Hum. Dev. 26, 169-180. doi: 10.1007/BF02353358

Gomes, H., Duff, M., Ramos, M., Molholm, S., Foxe, J. J., and Halperin, J. (2012). Auditory selective attention and processing in children with attentiondeficit/hyperactivity disorder Clin. Neurophysiol. 123, 293-302. doi: 10.1016/j.clinph.2011.07.030

Haines, M. M., Stansfeld, S. A., Head, J., and Job, R. (2002). Multilevel modelling of aircraft noise on performance tests in schools around Heathrow Airport London. J. Epidemiol. Community Health 56, 139-144. doi: 10.1136/jech.56.2.139 Haines, M. M., Stansfeld, S. A., Job, R. F., Berglund, B., and Head, J. (2001). Chronic aircraft noise exposure, stress responses, mental health and cognitive performance in school children. Psychol. Med. 31, 265-277.

Hall, J. W., Buss, E., and Grose, J. H. (2005). Informational masking release in children and adults. J. Acoust. Soc. Am. 118, 1605-1613. doi: 10.1121/1.1992675 
Hazan, V., and Barrett, S. (2000). The development of phonemic categorization in children aged 612. J. Phonetics 28, 377-396. doi: 10.1006/jpho.2000.0121

Hellbrück, J., and Liebl, A. (2007). "Effects of noise on cognitive performance: an overview and resent results," in Recent Topics in Environmental Psychoacoustics, ed S. Kuwano (Osaka: University Press), 153-184.

Hughes, R., and Jones, D. M. (2001). The intrusiveness of sound: laboratory findings and their implications for noise abatement. Noise Health 4, 51-70.

Hughes, R., Vachon, F., and Jones, D. M. (2007). Disruption of shortterm memory by changing and deviant sounds: support for a duplex-mechanism account of auditory distraction. J. Exp. Psychol. Learn. Mem. Cogn. 33, 1050-1061. doi: 10.1037/0278-7393.33.6.1050

Hughes, R., Hurlstone, M., Marsh, J., Vachon, F., and Jones, D. M. (2012). Cognitive control of auditory distraction. impact of task difficulty, foreknowledge, and working memory capacity supports duplexmechanism account. J. Exp. Psychol. Hum. Percept. Perform. 39, 539-553. doi: $10.1037 / a 0029064$

Hygge, S. (2003). Classroom experiments on the effects of different noise sources and sound levels on long-term recall and recognition in children. Appl. Cogn. Psychol. 17, 895-914. doi: 10.1002/acp.926

Hygge, S., Boman, E., and Enmarker, I. (2003). The effects of road traffic noise and meaningful irrelevant speech on different memory systems. Scand. J. Psychol. 44, 13-21. doi: 10.1111/1467-9450. 00316

Jamieson, D. G., Kranjc, G., Yu, K., and Hodgetts, W. E. (2004). Speech intelligibility of young schoolaged children in the presence of real-life classroom noise. J. Am. Acad. Audiol. 15, 508-517. doi: 10.3766/jaaa.15.7.5

Johansson, C. R. (1983). Effects of low intensity, continuous and intermittent noise on mental performance and writing pressure of children with different intelligence and personality characteristics. Ergonomics 26, 275-288. doi: $10.1080 / 00140138308963341$

Johnson, C. E. (2000). Children's phoneme identification in reverberation and noise. J. Speech Lang. Hear. Res. 43, 144-157.

Jones, D., Farrand, P., Stuart, G., and Morris, N. (1995). Functional equivalence of verbal and spatial information in serial short-term memory. J. Exp. Psychol. Learn. Mem. Cogn. 21, 1008-1018. doi: 10.1037/0278-7393.21.4.1008

Jones, D. M., Miles, C., and Page, J. (1990). Disruption of proofreading by irrelevant speech: effects of attention, arousal or memory? Appl. Cogn. Psychol. 4, 89-108. doi: 10.1002/acp.2350040203

Kassinove, H. (1972). Effects of meaningful auditory stimulation on children's scholastic performance. J. Educ. Psychol. 63, 526-530. doi: 10.1037/h0033747

Kintsch, W. (1988). The role of knowledge in discourse comprehension: a construction-integration model. Psychol. Rev. 95, 163-182. doi: 10.1037/0033-295X.95.2.163

Klatte, M., Lachmann, T., and Meis, M. (2010a). Effects of noise and reverberation on speech perception and listening comprehension of children and adults in a classroom-like setting. Noise Health 12, 270. doi: 10.4103/1463-1741.70506

Klatte, M., Lachmann, T., Schlittmeier, S., and Hellbrück, J. (2010b). The irrelevant sound effect in short-term memory: is there developmental change? Eur. J. Cogn. Psychol. 22, 1168-1191. doi: 10.1080/09541440903378250

Klatte, M., Hellbrück, J., Seidel, J., and Leistner, P. (2010c). Effects of classroom acoustics on performance and well-being in elementary school children: a field study. Environ. Behav. 42, 659-692. doi: 10.1177/0013916509336813

Klatte, M., Meis, M., Sukowski, H., and Schick, A. (2007). Effects of irrelevant speech and traffic noise on speech perception and cognitive performance in elementary school children. Noise Health 9, 64-74. doi: 10.4103/1463-1741. 36982

Kyriakides, L., Creemers, B., and Antoniou, P. (2009). Teacher behaviour and student outcomes: suggestions for research on teacher training and professional development. Teach. Teach. Educ. 25, 12-23. doi: 10.1016/j.tate.2008.06.001

Lecumberri, M. L. G., Cooke, M., and Cutler, A. (2010). Non-native speech perception in adverse conditions: a review. Speech Commun. 52, 864-886. doi: 10.1016/j.specom.2010.08.014

Leibold, L. J., and Neff, D. L. (2007). Effects of masker-spectral variability and masker fringes in children and adults. J. Acoust. Soc. Am. 121, 3666-3676. doi: 10.1121/1.2723664

Ljung, R., Sörqvist, P., and Hygge, S. (2009). Effects of traffic noise and irrelevant speech on children's reading and mathematical performance. Noise Health 11, 194-198. doi: 10.4103/1463-1741.56212

Ljung, R., Sörqvist, P., Kjellberg, A., and Green, A. (2009). Poor listening conditions impair memory for intelligible lectures: implications for acoustic classroom standards. Build. Acoust. 16, 257-265. doi 10.1260/135101009789877031

Marsh, J. E., Hughes, R. W., and Jones, D. M. (2009). Interference by process, not content, determines semantic auditory distraction. Cognition 110, 23-38. doi 10.1016/j.cognition.2008.08.003

Matheson, M., Clark, C., van Martin, R. K. E., Haines, M., Lopez Barrio, I., Hygge, S., et al. (2010). The effects of road traffic and aircraft noise exposure on children's episodic memory: the RANCH Project. Noise Health 12, 244-254. doi: 10.4103/1463-1741.70503

Maxwell, L. E., and Evans, G. W. (2000). The effects of noise on preschool children's pre-reading skills. J. Environ. Psychol. 20, 91-97. doi 10.1006/jevp.1999.0144

Mayo, C., Scobbie, J. M., Hewlett, N., and Waters, D. (2003). The influence of phonemic awareness development on acoustic cue weighting strategies in children's speech perception. J. Speech Lang. Hear. Res. 46, 1184-1196. doi: 10.1044/10924388(2003/092)

McCoy, S. L., Tun, P. A., Cox, L. C., Colangelo, M., Stewart, R. A., and Wingfield, A. (2005). Hearing loss and perceptual effort: downstream effects on older adults' memory for speech. Q. J. Exp. Psychol. A 58, 22-33. doi: 10.1080/02724980443000151

Metsala, J. L. (1997). An examination of word frequency and neighborhood density in the development of spoken-word recognition. Mem. Cognit. 25, 47-56. doi: 10.3758/BF03197284

Murphy, D. R., Craik, F. I. M., Li, K. Z. H., and Schneider, B. A. (2000). Comparing the effects of aging and background noise of short-term memory performance. Psychol. Aging 15, 323-334. doi 10.1037/0882-7974.15.2.323

Neath, I. (2000). Modeling the effects of irrelevant speech on memory. Psychon. Bull. Rev. 7, 403-423. doi 10.3758/BF03214356

Neuman, A. C., Wroblewski, M., Hajicek, J., and Rubinstein, A. (2010). Combined effects of noise and reverberation on speech recognition performance of normal-hearing children and adults. Ear Hear. 31, 336-344. doi 10.1097/AUD.0b013e3181d3d514

Nittrouer, S. (1996). The relation between speech perception and phonemic awareness: evidence from low-SES children and children with chronic OM. J. Speech Lang. Hear. Res. 39, 1059-1070.

Oh, E. L., Wightman, F., and Lutfi, R. A. (2001). Children's detection of pure-tone signals with random multitone maskers. J. Acoust Soc. Am. 109, 2888-2895. doi: $10.1121 / 1.1371764$

Oswald, C. J. P., Tremblay, S., and Jones, D. M. (2000). Disruption of comprehension by the meaning of irrelevant sound. Memory 8, 345-350. doi: 10.1080/09658210050117762

Pearson, D. A., and Lane, D. M. (1991). Auditory attention switching: a developmental study. J. Exp. Child Psychol. 51, 320-334. doi: 10.1016/0022-0965(91)90039-U

Pichora-Fuller, M. K., Schneider, B. A., and Daneman, M. (1995). How young and old adults listen to and remember speech in noise. J. Acoust. Soc. Am. 97, 593-608. doi: $10.1121 / 1.412282$

Rabbitt, P. M. A. (1968). Channelcapacity, intelligibility and immediate memory. Q. J. Exp. Psychol. 20, 241-248. doi: $10.1080 / 14640746808400158$

Röer, J. P., Bell, R., Dentale, S., and Buchner, A. (2011). The role of habituation and attentional orienting in the disruption of short-term memory performance. Mem. Cognit. 39, 839-850. doi: 10.3758/s13421-010-0070-z

Rogers, C. L., Lister, J. J., Febo, D. M., Besing, J. M., and Abrams, H. B. (2006). Effects of bilingualism, noise, and reverberation on speech perception by listeners with normal hearing. Appl. Psycholinguist. 27, 465-485. doi: 10.1017/S014271640606036X

Salamé, P., and Baddeley, A. (1982). Disruption of short-term memory by unattended speech: implications for the structure of working memory. J. Verbal Learn. Verbal Behav. 21, 150-164. doi: 10.1016/S00225371(82)90521-7

Schlittmeier, S. J., Weißgerber, T., Kerber, S., Fastl, H., and Hellbrück, J. (2012). Algorithmic modeling of the irrelevant sound effect (ISE) by the hearing sensation fluctuation strength. Atten. Percept. Psychophys. 74, 194-203. doi: 10.3758/s13414-011-0230-7

Schneider, B. A., Trehub, S. E., Morrongiello, B. A., and Thorpe, L. A. (1989). Developmental changes 
in masked thresholds. J. Acoust. Soc. Am. 86, 1733-1742. doi: 10.1121/1.398604

Seabi, J., Cockcroft, K., Goldschagg, P., and Greyling, M. (2012). The impact of aircraft noise exposure on South African children's reading comprehension: the moderating effect of home language. Noise Health 14, 244-252. doi: 10.4103/1463-1741.102963

Shield, B. M., and Dockrell, J. E. (2008). The effects of environmental and classroom noise on the academic attainments of primary school children. J. Acoust. Soc. Am. 123, 133-144. doi: 10.1121/1.281 2596

Söderlund, G., Sikström, S., and Smart, A. (2007). Listen to the noise: noise is beneficial for cognitive performance in ADHD. J. Child Psychol. Psychiatry 48, 840-847. doi: 10.1111/j.1469-7610.2007.01749.x

Söderlund, G., Sikström, S., Loftesnes, J., and Sonuga-Barke, E. (2010). The effects of background white noise on memory performance in inattentive school children. Behav. Brain Funct. 6, 55. doi: 10.1186/17449081-6-55

Sörqvist, P. (2010). Effects of aircraft noise and speech on prose memory: what role for working memory capacity? J. Environ. Psychol. 30, 112-118. doi: 10.1016/j.jenvp.2009. 11.004

Sörqvist, P., Nöstl, A., and Halin, N. (2012). Disruption of writing processes by the semanticity of background speech. Scand. J. Psychol. 53, 97-102. doi: 10.1111/j.1467-9450.2011.00936.x

Stansfeld, S. A., Berglund, B., Clark, C., Lopez-Barrio, I., Fischer, P., Öhrström, E., et al. (2005). Aircraft and road traffic noise and children's cognition and health: a cross-national study. Lancet 365, 1942-1949. doi: 10.1016/S01406736(05)66660-3

Steinbrink, C., and Klatte, M. (2008). Phonological working memory in German children with poor reading and spelling abilities. Dyslexia 14, 271-290. doi: 10.1002/dys.357

Szalma, J. L., and Hancock, P. A. (2011). Noise effects on human performance: a meta-analytic synthesis. Psychol. Bull. 137, 682-707. doi: 10.1037/a0023987

Talarico, M., Abdilla, G., Aliferis, M., Balazic, I., Giaprakis, I., Stefanakis, T., et al. (2007). Effect of age and cognition on childhood speech in noise perception abilities. Audiol. Neurotol. 12, 13-19. doi: 10.1159/000096153

Valente, D. L., Plevinsky, H. M., Franco, J. M., Heinrichs-Graham, E. C., and Lewis, D. E. (2012). Experimental investigation of the effects of the acoustical conditions in a simulated classroom on speech recognition and learning in children. J. Acoust. Soc. Am. 131, 232-246. doi: 10.1121/1.3662059

van Kempen, E., van Kamp, I., Lebret, E., Lammers, J., Emmen, H., and Stansfeld, S. (2010).
Neurobehavioral effects of transportation noise in primary schoolchildren: a cross-sectional study. Environ. Health 9, 2-13. doi: 10.1186/1476-069X-9-25

Werner, L. A. (2007). Issues in human auditory development. J. Commun. Disord. 40, 275-283. doi: 10.1016/j.jcomdis.2007.03.004

Wightman, F. L., Callahan, M. R., Lutfi, R. A., Kistler, D. J., and Oh, E. (2003). Children's detection of pure-tone signals: informational masking with contralateral maskers. J. Acoust. Soc. Am. 113, 3297. doi: 10.1121/1.1570443

Wightman, F. L., and Kistler, D. J. (2005). Informational masking of speech in children: effects of ipsilateral and contralateral distracters. J. Acoust. Soc. Am. 118, 3164-3176. doi: $10.1121 / 1.2082567$

Wightman, F. L., Kistler, D. J., and O'Bryan, A. (2010). Individual differences and age effects in a dichotic informational masking paradigm. J. Acoust. Soc. Am. 128, 270-279. doi: 10.1121/1.343 6536

Yacullo, W. S., and Hawkins, D. B. (1987). Speech recognition in noise and reverberation by school-age children. Audiology 26, 235-246. doi: 10.3109/00206098709 081552

Ziegler, J. C., Pech-Georgel, C., George, F., Alario, F., and Lorenzi, C. (2005). Deficits in speech perception predict language learning impairment. Proc. Natl. Acad. Sci.
U.S.A. 102, 14110-14115. doi: 10.1073/pnas.0504446102

Ziegler, J. C., Pech-Georgel, C., George, F., and Lorenzi, C. (2009). Speechperception-in-noise deficits in dyslexia. Dev. Sci. 12, 732-745. doi: 10.1111/j.1467-7687.2009.00817.x

Conflict of Interest Statement: The authors declare that the research was conducted in the absence of any commercial or financial relationships that could be construed as a potential conflict of interest.

Received: 14 May 2013; accepted: 12 August 2013; published online: 30 August 2013

Citation: Klatte $M$, Bergström $K$ and Lachmann $T$ (2013) Does noise affect learning? A short review on noise effects on cognitive performance in children. Front. Psychol. 4:578. doi: 10.3389/fpsyg. 2013.00578

This article was submitted to Developmental Psychology, a section of the journal Frontiers in Psychology. Copyright (c) 2013 Klatte, Bergström and Lachmann. This is an open-access article distributed under the terms of the Creative Commons Attribution License (CC BY). The use, distribution or reproduction in other forums is permitted, provided the original author(s) or licensor are credited and that the original publication in this journal is cited, in accordance with accepted academic practice. No use, distribution or reproduction is permitted which does not comply with these terms. 